\title{
How Peer Review Affects Chinese College Students' English Writing Abilities
}

\author{
Chunlin Yao \\ College of Foreign Languages in Hebei United University, Tangshan, China \\ Email: yao_chunlin@yahoo.com \\ Hongmei Cao \\ Minzu University of China, Beijing, China \\ Email: honey9mail@yahoo.com.cn
}

\begin{abstract}
The quantitative study investigates whether the method peer review can improve Chinese college students' English writing abilities. The subjects are 64 students from Minzu University of China. The research finds that the method peer review can improve the students' writing level and be appreciated by most students because it has many advantages. For example, peer review helps students to revise their papers, to improve the content and organization of their writing and to build interest and confidence in English writing. On the other side, a few students regret it, as they feel instinctively that only a better writer (or a native speaker) is qualified to judge or comment on their written work, or they think that peer review consumes time. The author believes that systematic training can help Chinese college students review their peers' paper better.
\end{abstract}

Index Terms - peer review, Chinese college students, English writing

\section{Why Chinese College Students ARe Afraid of ENGLish Writing}

Almost all students in china student English from elementary school to college. That is to say, Chinese college students have studied English for more than ten years. But some students can not write an English paper well. More badly, some students are afraid of English writing. What's the reason for that? In my opinion, the English language abilities and the psychological Obstacles affect their English writing.

Generally speaking, writing in English is a complex, recursive and problem-solving process, which involves thinking in conscious and goal-directed episodes. In the composing process, the writers need to demonstrate the control of a number of variables simultaneously, including the control of content, format, sentence structure, vocabulary and punctuation, spelling and letter formation at the sentence level. Beyond the sentence, the writer must be able to structure and integrate information into cohesive and coherent paragraphs and texts. All this cause the writers a great many difficulties.

Usually, Chinese students are not good at grammar and English writing styles, so it is difficult for them to make up sentences and as a result, Chinglish (Chinese English) can be seen in the students' writing. Due to a small vocabulary, they can't think of the proper words that they have learned to express themselves and spell them correctly. Besides, they cannot use proper conjunctions and transitional words, and have difficulty in thinking of varied words, expressions or sentence structures.

\section{A. The Limitation of English Vocabulary}

Some students report that they cannot think of the related words to express ideas in English for the lack of vocabulary. Most students find that deficient vocabulary is the main reason for their frustration in expressing ideas. They find it difficult to convey what they have known and want to say due to the limitation of vocabulary. They often have to give up some good ideas because they can not find appropriate words to express them. Instead, they write down simple ideas by using those easy and simple words that they have known. Appropriate use of vocabulary and expressions is a mark for one's maturity in language use. Repetitive and monotonous use of vocabulary and sentence structures makes the readers dull. Most students know this clearly, but they still stick to the simple and monotonous vocabulary. They explain that they practice writing only to pass a lot of exams. In order to get higher scores, they prefer to use the familiar and simple words to avoid making mistakes. Thus, the students' compositions appear to be monotonous, repetitive and boring.

Most students report that they translate their thoughts from Chinese into English when they are writing. When they are translating, they always try to find the word-to-word equivalents. Some students say that they cannot use words to express meaning precisely or appropriately. They fail to choose precise words in English to convey the exact meaning. They tend to put words in the wrong places or they do not know what words to use to express their ideas. It is also difficult for them to distinguish between formal words and informal words. When learning new words by heart, many students just remember the Chinese meaning, ignoring the using conditions such as the formal and informal context. They are uncertain about the usage of words. They are confused by words of similar meanings and do not know which 
ones to choose in order to be exact. Due to confusion about word choice, they tend to use words repeatedly. But in fact, no two words are quite alike. Few words in context can be fully defined in terms of their denotations or their explicit dictionary meanings alone. Almost all words carry connotations, or implicit meanings, as well. They suggest or call to mind associations beyond their literal meaning.

\section{B. Be Poor in English Grammar}

Some students announce that they are poor in English grammar. Grammar is a very complicated problem for the students. They make a lot of grammatical errors in tense, singular/plural form, punctuation, and so on. That is probably due to the differences between English and Chinese grammatical rules, since the two languages belong to different language families, with one in the Indo- European language family and the other in the Sino-Tibetan language family. Most students argues that tense is the most troublesome. There are sixteen tenses in English. Students are confused with which tense is the correct one. The same verb, with different tenses, conveys different meanings. Influenced by their knowledge of Chinese, many students are often puzzled by the various English tenses. Making grammatical errors seem inevitable for most of them and the most common errors are the disagreement of subject and verb, the negative expression, the disagreement of tense, the misusing of mood and clauses, etc.

Another problem that the students are confused with is the singular/plural form of nouns. In English, some nouns have plural number and singular number while some do not. Because some nouns do, there is the problem of agreement between some parts in a sentence such as the agreement between the subject and the predicate, nouns and their pronouns, nouns and their possessive forms, etc.

Besides, students also have difficulties in articles and prepositions. Articles in English are too difficult for Chinese college students. It is not only because there are no articles at all in Chinese but also because there are many exceptions in the English grammar about articles (Zhang, 1995). Prepositions are also very troublesome. Modern English belongs to the analytic languages in which the relationships between the words in a sentence are not indicated by the changes of the word forms but by the word order and collocation between words. To show the collocation relationship, prepositions play a very important role. That is why there are often many more prepositions used in a sentence in English than in Chinese. Influenced by Chinese, students often make mistakes in whether or not to use a preposition and in choosing an appropriate one.

\section{Difficulty in Generating Ideas}

Some students say their mind seem to go blank when they start to work on an English composition. Having nothing to write is their main problem. They say sometimes they do not have any experience with the topic, or have few feelings to share with others. Therefore, they tend to write around few points repeatedly, which makes the article monotonous. Their limited life experience and lack of independent thinking make their writing short of content. It seems that facing an empty paper, the students are also struggling with an empty mind.

\section{Unfamiliarity with English Organization}

Some students admit that they have great difficulty in organizing their ideas in an English writing class. Some students admit that their biggest problem is the unfamiliarity with English discourse pattern. They say that they do not have a clear idea about how to organize writing well, and do not know how to combine sentences together in a paragraph. Usually their compositions lack topic sentences, unity or coherence, and lost the connection with the topic of the paragraphs. Sometimes, they often follow a Chinese way of composing an English composition. They believe that it is not the best way to write, but they think it is the easiest and fastest way. When other students are asked whether the unfamiliarity with English organization is a big obstacle to their writing, most of them reported that they do not notice it. Some of them even say that they do not think there are differences between Chinese and English discourse patterns. This may be due to their low proficiency. In the writing process, students are so busy in struggling with the vocabulary and grammar problems and they spare little time or attention to the discourse patterns. Besides, in the teachers' feedback to students' compositions, they lay great emphasis on the students' grammatical and vocabulary mistakes. Accuracy and correctness are emphasized in writing class while little attention is paid to the differences between Chinese and English discourse patterns.

\section{E. Psychological Obstacles of English Writing}

"From the aspect of educational psychology, the main factor which affects the students during the process of study is the control of their emotions (Shu \& Zhuang, 1996, p.46)." The emotional factor referred to the block to study a certain foreign language caused by the psychological factors of the learners. When a student is exposed to a new language, the psychological obstacles are the emotional state and motivation. It is one of the main effects on the learners' studies and the first block of the effect of foreign language study.

According to Krashen (1985), motivation, self-confidence and anxiety are the three main emotional factors which cause the psychological obstacles. Practice proves that the students' learning motivation and attitudes are directly connected with their aims. Chinese students' learning aims and motivations may be for passing the exams in the college or finding a good job in some foreign companies. Their attitudes towards writing are negative. Psychologically, the students regard writing as a headache task and make it the last thing to be practiced. They lose confidence in writing and 
feel nervous about it. In their opinion, they cannot make much progress in writing even if they work hard and write once or twice a week; writing a composition will cost them too much time and it is no use. The following is the analysis of their psychological obstacles.

First, their psychological obstacles come from the students' characters. According to psychology, some people are extroverted while others are introverted. The extroverted students are quick in mind. They are active in class and brave to speak. Besides, their activities are easy to arouse. However, the introverted students are not confident enough to take part in the activities on class. Usually they are too quiet in class and their activities are difficult to arouse. However, only a small number of the students are completely extroverted or introverted in a class. The majorities of the students are neither extroverted nor introverted. Their enthusiasm must be stimulated by the interestingly designed teaching.

Besides, most of Chinese students are the only child in their families. They are dependent on others not only in their lives but also in their studies and are easy to be discouraged. As a result, the anxiety caused by the failure in their studies will make them lose confidence. In fact, no matter what kind of students they are, repeated failure is likely to bring them pressure, which may affect them positively or negatively. The positive effect does well to their studies while the negative effect is sure to hinder their studies. Such conditions are more likely happen to freshmen, who haven't got used to the new study life in the college.

Second, psychological obstacles come from teachers' and parents' attitude and evaluation. Teachers' attitude and evaluation have a direct effect on students' confidence. Scientific, objective and positive evaluation from teachers is the main factor to help students to build up their confidence. Unfortunately, a lot of teachers think it is not necessary to praise the students for their advantages for fear that they may become too proud. On the contrary, they criticize the students for their mistakes, and teachers think only in this way can they correct their mistakes. So the teachers keep criticizing, blaming and denying the students instead of encouraging, praising and affirming them. If the teachers always doubt the students' attitudes to their studies and their ability to study, the students will act recklessly because they think they can never do well no matter how hard they work.

Similarly, if the parents expect too much of their children, complain too much of the failure in their studies, are too strict with them or just let them alone, the children will also feel discouraged and lose confidence. Thus, to prevent their shortcomings from being found, they seldom speak to others and seldom take part in the activities in class. As time goes on, they become introverted, self-abased, and inactive. Worse still, they may become afraid of difficulty in their studies. Once this kind of attitude is formed, its bad effect will be prefunded and lasted.

Finally, the management of class can cause psychological obstacles. In a traditional class, the teachers are the authority and the students must absolutely obey their teachers' orders. Usually, the students just sit there and listen to their teachers, taking notes of what the teachers have said. They are not supposed to have their own opinions. Instead, they are just like "containers" used to contain what the teachers have taught. This class atmosphere make the students lose the sense of safety and become anxious. Under these conditions, the students are slow in thinking and can not express themselves very well. If things continue in this way, the students will lose interest in thinking by themselves, and will not get to the bottom of things that they have learned. As a result, they lose the interest of studying. Of course the same things happen in English writing teaching. Traditionally, teachers only give the students a writing topic and order them to finish it in the set time, without instruction or discussions. After being finished, the compositions are collected and evaluated in the traditional way, that is, every mistake is pointed out and corrected and then all the compositions are covered with red marks.

\section{How to IMPRove Chinese College StUdents' Writing SKILls}

In order to improve the students' English writing ability, a lot of educators devote themselves to the research of English writing teaching in Chinese context and a lot of methods come into being. Among them, the peer review method is especially attractive.

Many researchers have studied peer review in second language (L2) writing (Mangelsdorf, 1992; Sengupta, 1998; Cosh, 1999; Spratt \& Leung, 2000; DiGiovanni \& Nagaswami, 2001; Rollinson, 2005). In the process of second language writing, peer review means "students read each other's drafts and make suggestions for revision." (Mangelsdorf, 1992, p.274) All the researchers suggested teachers in second language writing to use the method of peer review, even in online learning. DiGiovanni and Nagaswami (2001) believe "ONPR (online peer review, the author explained) could become an exciting new teaching/learning tool available to both L2 teachers and students in today's networked or virtual classrooms" (p. 269).

Peer review has at least two characters.

Firstly, peer review operates on a more informal level than the teacher-centered review, where one teacher provides all students feedback. It gives the students the opportunity to communicate with each other, and meaning is negotiated between the two parties. That is to say, peer review changes the one-way interaction between the teacher and students, where students may disagree with or even understand the teacher's authority comment to the two-way interaction between students, where students can exchange their opinions well. "In any case, teacher feedback may not be nearly as effective as has been believed. There may in fact be many deficiencies in the written comments of teachers: they have been criticized as being unspecific, incomprehensible, contradictory, inconsistent, inaccurate, meaningless to the students, ague, over-general, abstract, formulaic and idiosyncratic.” (Zaml, as cited in Rollinson, 2005, p.25) 
Secondly, peer review is that peers can spend much more time providing feedback on an individual draft than the teacher-centered review. It is an immediate process between writing and receiving feedback. Thus there is a more immediate interaction between writer and reader.

Some researches in Europe or America have shown that the method of peer review can improve students' second language writing ability (Mangelsdorf, 1992; DiGiovanni, E. \& G. Nagaswami, 2001). As we know, in China the English class is usually a teacher-centered class. Students prefer their teacher to guide their learning. Whether peer review can benefit Chinese college students in English writing? What do students gain from this teaching method? What are its limitations? How should we improve this method so that students from various backgrounds and ability levels can benefit from it? This paper presents tentative answers to these questions based on a case study.

\section{A Case Study: Did Peer Review Can Help Chinese College Students Improve Their Writing Abilities}

I taught two classes (32 students in each class) in Minzu University of China in the first semester of 2010-2011. At the beginning of the semester, I asked the students to write two papers in two hours and invited three teachers (Professor Cao, Professor Qiao, Professor Hou) to check the students' English writing level. T-test examination proclaimed the students in different class are at the same level in English writing. The mean score was 77.9 VS. 78.4 (see table 1).

TABLE 1:

\begin{tabular}{lllllll}
\multicolumn{8}{c}{ STATISTICS OF THE WRITING SCORES FOR THE PRE-TEST } \\
\hline \multirow{2}{*}{ Score } & Group & $\boldsymbol{N}$ & Mean & Std. Deviation & Std. Error Mean & Sig. \\
& EG & 32 & 77.94 & 5.775 & 1.491 & \multirow{2}{*}{0.615} \\
& CG & 32 & 78.44 & 6.770 & 1.748 & \\
\hline
\end{tabular}

In the next semester, all the students were required to write eight papers (two papers per week) and one class is regarded as a controlled class, the other class as an experimental class. In the controlled class, the teacher reviewed students' paper. In the experimental class, the students were formed as eight groups at random (four students for each group). One group reviewed other group's paper. That is, the first group reviewed the second group's paper, the second group reviewed the third group's paper........and the eighth group reviewed the first group's paper at their first paper; while for the second paper, the first group reviewed the third group's paper, the second group reviewed the fourth group's paper........and the seventh group reviewed the first group's paper, and the eighth group reviewed the second group's paper, and so forth. The group worked together for one paper. If they had different views on the same paper, they could ask me for help and I was the final judge.

At the end of the semester, all the students were required to write two papers in two hours and I invited those three teachers (Professor Cao, Professor Qiao, Professor Hou) again to check the students' English writing level. T-test examination proclaimed the students who were in the experimental class got the higher mean score than those in the controlled class (87.6 VS. 81.2) and the differences was significantly $(\mathrm{P}=0.000)$ (see table 2).

TABLE 2:

\begin{tabular}{lllllll}
\multicolumn{8}{c}{ STATISTICS OF THE WRITING SCORES FOR THE POST-TEST } \\
\hline \multirow{2}{*}{ Score } & Group & $\boldsymbol{N}$ & Mean & Std. Deviation & Std. Error Mean & Sig. \\
& EG & 32 & 87.64 & 5.106 & 1.318 & \multirow{2}{*}{0.000} \\
& CG & 32 & 81.23 & 5.317 & 1.373 & \\
\hline
\end{tabular}

After the examination, I asked the monitor to review the students in the experimental class about their view about peer review in English writing and the monitor must write down all the views anonymously (usually Chinese student don't criticize their teacher's teaching method, but they often comment on their teacher' teaching method among themselves).

\section{Discussion}

\section{A. The Advantages of Peer Review}

Firstly, Peer review helps students to improve the content and organization of their writing. It leads students to consider different ideas about their topics and helps them to develop and clarify these ideas.

Secondly, peer review helps students learn from their audience responses. That is to say, peer review is a process of moving away from writer-to-reader based prose. When students review a paper, at the same time, they learn how to write a paper well from the reader's aspect. As Mangelsdorf (1992) pointed out that peer review helps "reinforce the idea that the purpose of writing is communication...real audience, real purpose" (p.279).

Thirdly and most importantly, peer review helps students not only build interest and confidence in their abilities to write a text but also evaluate it. In the process of peer review, students actively participated in learning. They were not passive sponges. As Rollinson (2005) pointed out: "By giving the students practice in becoming critical readers, we are at the same time helping them towards more self-reliant writers, who are both self-critical and who have the skills to selfedit and revise their writing" (p.29). 
Just as everything has two sides, some students believe that peer review also has its limitations.

Firstly, some students rejected peer review because they feel instinctively that only a better writer-or a native speaker - is qualified to judge or comment on their written work. They don't think that they, or their peers, could be good critics. The idea that learning is only possible from an authority figure who knows "correct" English makes students against peer review.

Secondly, some students rejected peer review because they think that peer review consumes time. Whether feedback is given in the means of speaking or writing, the peer review itself is a lengthy one. Reading a draft (probably more than once), making notes, then writing the comments, or engaging orally with the writer in a feedback circle, will consume a significant amount of time.

\section{Solutions to the Limitations of Peer Review}

Most of the potential problems above, including both practical and pedagogical issues can be alleviated by: properly establishing effective procedures and adequate training. The training includes coaching students in the principles and practices of effective peer group interaction and response. Without such training, it is more likely that peer review will be destructive and tactless. It may also tend towards dealing with surface matters rather than issues of meaning, content and organization. In one word, "it is not fair to expect that students will be able to perform these demanding tasks without first having been offered organized practice with and discussion of the skills involved" (Stanley, as cited in Rollinson, 2005, p.26).

In the training teachers should alter students' traditional attitudes against peer review. At the beginning, students may be against peer review, especially the students who are from teacher-centered culture. It is better for teacher to teach students how to do peer review, and to check the peer review, and appropriate the students who do a better peer review. After a short period, students may establish trust between each other, and they may found peer review is beneficial to them.

In the training teachers also should make students know that peer review is a time consuming but not time wasting activity. Peer review helps the students to get a better overlook on how to write successfully - in organization and content. The process for students revising other's drafts is a process of learning how to write well also. So, peer review is beneficial to students thought it consumes more time.

At last, the students will undoubtedly do peer review well if they have a positive attitude toward peer review. Then, it is unnecessary for the teacher interferes with peer review.

\section{CONCLUSION}

Peer review has its advantages and disadvantages. It helps students to improve their writing skills, to built interests and confidence in writing. Though a few students may reject it for some reasons, they would like it after improving its limitations. It is a beneficial practice to both students and teachers in second language writing if the class is adequately set-up and the students are trained before peer review. It is a potentially rewarding option.

\section{ACKNOWLEDGMENT}

The research is supported by Doctoral Social Science Foundation of Heibei United University (河北联合大学博士科 研启动项目). I give my warm thanks to Heibei United University.

\section{REFERENCES}

[1] Cosh, J. (1999). Peer observation: a reflective model. ELT Journal, 53,22-27.

[2] DiGiovanni, E. \& G. Nagaswami. (2001). Online peer review: an alternative to face-to-face? ELT Journal, 55, 263-270.

[3] Krashen, S. D. (1985). The Input Hypothesis. London: Longman,.

[4] Mangelsdorf, K. (1992). Peer reviews in the ESL composition classroom: what do the students think? ELT Journal, 46, $274-$ 284.

[5] Rollinson, P. (2005). Using peer feedback in the ESL writing class. ELT Journal, 59, 23-31.

[6] Sengupta, S. (1998). Peer evaluation: 'I am not the teacher'. ELT Journal, 52,19-28.

[7] Spratt, M. \& B.Leung. (2000). Peer teaching and peer learning revisited. ELT Journal, 54, 218-226.

[8] Zhang, Z. X. (1995). The Main English Writing Teaching Problems in China. Foreign Langauge Teaching and Research, 4,4349.

[9] Shu, D. F. \& Z. X. Zhuang. (1996). Modern Foreign Langauge Teaching. Shanghai: Shangahi Foreign Language Education Press.

Chunlin Yao was born in Tangshan, China in 1974. He received his PH.D. degree in Arts (Linguistics and Applied Linguistics) from Minzu University of China, Beijing, China in 2011.

$\mathrm{He}$ is currently a lecture in the College of Foreign Languages of Hebei United University, Tangshan, China and a postdoctoral researcher in Chinese Academy of Social Sciences in China, Beijing, China. His research interests include Sociolinguistics and Language Learning. 
Hongmei Cao was born in Meihekou, China in 1979. She received his Master degree in Arts (Linguistics and Applied Linguistics) from Minzu University of China, Beijing, China in 2010.

She is currently a lecture in the Preparatory College of Minzu University of China, Beijing, China and a doctor candidate in Minzu University of China, Beijing, China. Her research interests include Sociolinguistics and English Teaching. 